\title{
УДК 615.825.6
}

\section{МЕТОДЫ ЭКСПЕРИМЕНТАЛЬНОЙ ПЕДАГОГИЧЕСКОЙ РАБОТЫ В ФИЗИЧЕСКОМ ВОСПИТАНИИ ПОДРОСТКОВ С ИДИОПАТИЧЕСКИМ СКОЛИОЗОМ II-III СТЕПЕНИ}

\author{
Васильев Виктор Андреевич \\ преподаватель каф. ТиМ АФК \\ Научный руководитель: Бегидова Тамара Павловна \\ к.п.н., профессор \\ ФГБОУ ВО «Воронежский государственный \\ институт физической культуры»
}

Аннотация: Вопросы коррекции сколиотических деформаций позвоночника являются актуальной проблемой медицины и адаптивной физической культуры. Механизмы, вызывающие развитие идиопатического сколиоза не выявлены даже силами современной науки. Однако, в XX веке в науке появились концепции эффективной консервативной терапии сколиотических деформаций с применением корсетотерапии и специфических сколиозу упражнений. Критерии эффективности применяемых упражнений остаются размытыми и поныне. Авторами статьи предпринимается попытка систематизировать методы экспериментальной педагогической работы, применяемые в физическом воспитании подростков с идиопатическим сколиозом.

Ключевые слова: сколиоз, деформация, педагогическое наблюдение, тестирование, анкетирование, электропунктурная диагностика, электромиография, математическая статистика.

\section{METHODS OF EXPERIMENTAL PEDAGOGICAL WORK IN PHYSICAL EDUCATION OF ADOLESCENTS WITH IDIOPATHIC SCOLIOSIS OF THE II-III DEGREE}

\section{Vasiliev Viktor Andreevich Scientific supervisor: Tamara Pavlovna Begidova}

Abstract: The issues of correction of scoliotic deformities of the spine are an urgent problem of medicine and adaptive physical culture. The mechanisms that 
cause the development of idiopathic scoliosis have not been identified even by the forces of modern science. However, in the twentieth century, the concepts of effective conservative therapy of scoliotic deformities with the use of corset therapy and specific scoliosis exercises appeared in science. The criteria for the effectiveness of the exercises used remain blurred to this day. The authors of the article attempt to systematize the methods of experimental pedagogical work used in the physical education of adolescents with idiopathic scoliosis.

Key words: scoliosis, deformity, pedagogical observation, testing, questionnaire, electropuncture diagnostics, electromyography, mathematical statistics.

Сколиотическая болезнь является достаточно распространенным заболеванием и основанием для включения учащихся в специальную медицинскую группу. В рамках исследовательской работы одной из поставленных задач является определение особенностей функционального состояния подростков специальной медицинской группы со сколиозом, имеющих сопутствующие патологические отклонения.

Предваряя решения поставленной задачи, необходимо раскрыть сущность методов, используемых на протяжении исследования. Для определения функционального состояния учащихся будут использоваться следующие методы: педагогическое наблюдение, тестирование с целью оценки физического развития, функциональное тестирование, анкетирование, метод электропунктурной диагностики, метод электромиографии, методы математической статистики.

Педагогическое наблюдение. Метод, реализуемый на протяжении всего периода исследования. Необходимо организовать систематические наблюдения за различными сторонами деятельности школьников специальной медицинской группы на занятиях по адаптивному физическому воспитанию. Должно учитываться отношение учащихся к различным средствам адаптивного физического воспитания, к индивидуальным занятиям, комплексам корригирующей гимнастики и силовым упражнениям. Должно отмечаться наличие желания заниматься адаптивной физкультурой, осваивать предложенные упражнения, способности к преодолению трудностей, реакции на неудачу, настроения в ходе учебных занятий.

Тестирование с целью оценки физического развития. Измерение параметров физического развития испытуемых будет осуществляться следующим образом: 
- длина тела (см) измеряется с помощью ростомера;

- вес (кг) измеряется с помощью медицинских весов;

- окружность грудной клетки (ОКГ, см) измеряется сантиметровой лентой, которая сзади проходит под углами лопаток, спереди ниже грудных желёз;

- жизненная ёмкость лёгких (ЖЕЛ, л) - измерения проводятся 2-3 раза через 0,5-1 мин. Фиксируется лучший результат;

- кистевая динамометрия (кг) - для измерения используется кистевой динамометр. Испытуемый держит динамометр в кисти, отведя прямую руку в сторону, сжимает динамометр. Измерения проводятся 2-3 раза с периодом 0,51 мин. Лучший результат будет фиксироваться [6, с. 58].

Функциональное тестирование. Проба Штанге - проба с задержкой дыхания на вдохе до и после физической нагрузки. Испытуемый в положении стоя делает пробный вдох, затем полностью выдыхает воздух и после полного (но не предельного) вдоха задерживает дыхание (зажимает нос). В момент начала задержки дыхания включается секундомер, это первая фиксация времени. Вторая фиксация времени происходит при невозможности дольше задерживать дыхание.

Проба Генча - проба с задержкой дыхания на выдохе. Проба выполняется так же после пробного вдоха и выдоха. Сделав вдох, испытуемый делает спокойный глубокий (но не предельно возможный) выдох и задерживает дыхание (зажимал нос). С момента задержки дыхания включается секундомер, который останавливался при первом вдохе.

При проведении проб с задержкой дыхания не рекомендуется задерживать дыхание «через силу». Длительность времени задержки дыхания и его оценка определяется периодом, в течение которого испытуемый спокойно, без волевого напряжения может воздерживаться от вентиляции легких [3, с. 96].

Пробы Штанге и Генча отражают способность организма к работе в условиях кислородной недостаточности [5, с. 15].

Оценка ЧСС осуществляется пальпаторно на лучевой артерии.

Артериальное давление измеряется при помощи тонометра и фонендоскопа по методу Короткова.

Индекс Руффье. Испытуемым измеряется пульс в положении сидя (P1), затем предлагается выполнить 30 приседаний за 30 сек. После этого подсчитывается пульс стоя (P2), а затем - через 1 минуту отдыха (Р3). 
Оценка индекса производится по формуле $1=((P 1+P 2+P 3)-200) / 10$. Индекс оценивается: $<0$ - отлично, 1-5 - хорошо. 6-10 - удовлетворительно. 11-15 слабо, $>15$ - неудовлетворительно. [3, с. 125]

Ортостатическая проба служит для характеристики функциональной полноценности рефлекторных механизмов регуляции гемодинамики $[4$, с. 165]. У исследуемого после 5 мин. пребывания в положении лежа дважды подсчитывается ЧСС и измеряется артериальное давление (АД). Затем по команде он спокойно (без рывков) занимает положение стоя. ЧСС подсчитывается на 1-й и 3-й минутах пребывания в вертикальном положении. АД определяется на 3-й и 5-й минутах.

Ортостатическая проба является объективной оценкой рефлекторных механизмов регуляции гемодинамики и оценки возбудимости центров симпатической иннервации. Возбудимость центров симпатической иннервации определяется по степени учащения пульса, а полноценность вегетативной регуляции по времени стабилизации пульса.

Коэффициент выносливости (КВ) Определяется по формуле Кваса. Коэффициент характеризует функциональное состояние сердечно-сосудистой системы. Этот тест, рассчитывается по следующей формуле: КВ=(ЧСС * 10) / пульсовое давление. В норме КВ=16. Увеличение его указывает на ослабление деятельности сердечно-сосудистой системы, уменьшение - на усиление. [3]

Анкетирование. Для учащихся специальной медицинской группы со сколиозом разрабатывается анкета с целью оценки анамнестических данных и определения степени мотивированности к учебному процессу. Входящие в неё вопросы предполагают как стандартизированный ответ, так и ответ, даваемый в относительно свободной форме, избираемый произвольно самим испытуемым. Среди вопросов особое внимание уделяется проблеме двигательного развития, наличию патологий в родовом периоде, травм, сопутствующих заболеваний и особенностям двигательного режима в подростковом возрасте.

Метод электропунктурной диагностики. Метод электропунктурной диагностики (ЭПД) функционального состояния меридианов основан на измерении электрокожного сопротивления (ЭКС) в репрезентативных активных точках (ТА). ЭКС измеряется с помощью электрического детектора.

Электрическая кожная проводимость зависит, прежде всего, от состояния симпатической части вегетативной нервной системы (ВНС), стволовых структур мозга и ретикулярной формации. 
Большинство таких точек располагаются в области лучезапястного сустава и области стопы [2, с. 32].

Обследование должно проводиться в комфортных условиях, в горизонтальном положении в состоянии покоя, не раньше, чем через час после приема пищи. В чашечку поискового электрода закладывается смоченный в растворе поваренной соли ватный тампон (физиологический раствор).

Полученные результаты заносятся в специальную таблицу. Эта таблица составляется с учетом среднего значения электропроницаемости меридианов у здоровых людей. Затем все показатели измерений суммируются, и находится среднее арифметическое величин электропроницаемости всех меридианов.

Полученная средняя величина помещается в таблицу. Выше и ниже этой линии на 7 мм проводятся две линии, которые образуют так называемый физиологический коридор.

Если показатели измерения соответствующего меридиана выше указанного коридора, то соответствующий меридиан находится в состоянии избыточности, а если ниже - то в состоянии недостаточности. При интерпретации результатов этих исследований практическое значение будут иметь не столько абсолютные значения измерений отдельных меридианов, сколько их соотношения.

ЭМГ или метод электромиографии предполагает аппаратное исследование, благодаря которому можно определить степень проводимости нервных окончаний и электрической активности мышц. Преимущественно используются накожные электроды, крепящиеся к брюшку исследуемой мышцы. Эти датчики улавливают колебания потенциалов, отображая их на мониторе или записывая на магнитный носитель. Отличительными особенностями метода является безболезненность и безвредность, в связи с этим метод получил широкое распространение в физической реабилитации. Диагностика может осуществляться как в состоянии покоя, так и в состоянии произвольного или тонического мышечного напряжения, давая полную диагностическую картину состояния нервной системы и мышц [7, с. 15].

Методы математической статистики. Данные, полученные в процессе исследования, будут подвергнуты математической обработке. С целью определения статистических зависимостей будут применяться общепринятые способы обработки полученных в экспериментальных исследованиях результатов [1, с. 25]. 
При выявлении достоверности различий результатов контрольной и экспериментальной групп будет использоваться $\mathrm{t}$-критерий Стьюдента. Различия считаются статистически достоверными при 5\% уровне значимости $(\mathrm{P}<0,05)$, что признается вполне надежным в педагогических исследованиях.

Результаты тестирования будут внесены в электронные таблицы и обработаны программой обработки электронных таблиц Excel. Расчеты выполняются на персональном компьютере по стандартным программам.

Специфичность диагностики, непредсказуемость течения и сложность в коррекции сколиотической болезни требует для детального изучения применения различных методов исследования - характерных как для адаптивной физической культуры, так и для спортивной медицины - от наблюдения и анкетирования до проведения функциональных проб с применением специального оборудования. Подробное тестирование функционального состояния, дополненное анкетированием, позволит дать оценку качественных изменений функционального состояния и улучшения качества жизни в исследуемой группе. Использование методов математической статистики дает возможность подтвердить эффективность методик коррекции сколиотической болезни, реализуемых в процессе занятий адаптивной физической культурой.

\section{Список литературы}

1. Боровиков В.П. Популярное введение в программу STATISTIKA. - M.: Компьютер Пресс, 1998. - 267 с.

2. Воинова Л.В. Учебное пособие по оценке функционального состояния организма по методу Накатани «Медискрин»: учеб. - метод. пособие., М: HTC, 2002. $-58 \mathrm{c}$.

3. Геселевич В.А. Медицинский справочник тренера. - 2-е изд., доп. и перераб. - М.: Физкультура спорт, - 1981. - 271 с.

4. Дубровский В.И. Спортивная медицина: учебн. для студ. высш. учеб. заведений. - 2-е изд., доп. - М.: Гуманит. изд. центр ВЛАДОС, 2002. - 512 с.

5. Ишал В.А. Ортоспондилография и так называемый физиологический сколиоз // Ортопедия, травматология и протезирование. - 1983. - №5. - с. 16-20.

6. Корнилов Н.В., Грязнухин Э.Г. Ортопедия: Краткое руководство для практических врачей // СПб., 2001. - 320 с.

7. Санадзе А.Г., Касаткина Л.Ф. Клиническая электромиография для практических неврологов. - М.: ГЭОТАР-Медиа, 2020. - 80 с. 